\title{
IMPLEMENTASI PROGRAM GERAKAN LITERASI SEKOLAH BERBASIS PEMBELAJARAN MULTILITERASI DI SDN 1 KOBA
}

\author{
Nurjanah $^{1}$, Yurdayanti $^{2}$ \\ ${ }^{1,2}$ STKIP Muhammadiyah Bangka Belitung \\ ${ }^{1}$ nurjanah@stkipmbb.ac.id, ${ }^{2}$ yurdayanti@stkipmbb.ac.id
}

\begin{abstract}
Abstrak
Artikel ini bertujuan untuk mendalami pelaksanaan program GLS di SDN 1 Koba Kabupaten Bangka Tengah. Jenis penelitian ini yaitu penelitian kualitatif dengan pendekatan studi kasus. Lokasi penelitian di SDN 1 Koba Kabupaten Bangka Tengah. Subjek penelitian yaitu Kepala Sekolah, Guru, dan Peserta Didik. Teknik pengumpulan data yang digunakan yaitu wawancara, observasi, dan dokumentasi. Hasil penelitian menunjukkan bahwa pelaksanaan program gerakan literasi sekolah di SDN 1 Koba Kabupaten Bangka Tengah berada pada tahap pembiasaan. Upaya-upaya yang dilakukan sekolah dalam melaksanakan program gerakan literasi sekolah, yakni (1) Membaca 15 menit sebelum Pelajaran, (2) Membuat Pojok Literasi dan Lingkungan yang Kaya Teks, (3) Pembelajaran Multiliterasi Membaca dan Menulis. Adapun kendala yang dihadapi sekolah dalam pelaksanaan GLS, yakni (1) Rendahnya kesadaran guru terhadap pentingnya kegiatan literasi, (2) Sebagian guru pada kelas tinggi masih kurang disiplin, (3) Jumlah buku fiksi atau buku cerita bergambar di perpustakaan sekolah masih kurang memadai, (4) Sebagian guru tidak memahami contohcontoh penerapan gerakan literasi.
\end{abstract}

Kata Kunci: Gerakan Literasi Sekolah; Sekolah Dasar; Multiterasi.

\begin{abstract}
This article aims to explore the implementation of GLS in SDN 1 Koba, Central Bangka Regency. This type of research is a qualitative descriptive study. The research location was at SDN 1 Koba, Central Bangka Regency. The subjects of the study were the Principal, Teachers, and Students. The research instruments used were interviews, observation, and documentation. The results showed that the implementation of the school literacy movement program at SDN 1 Koba, Central Bangka Regency was at the habituation stage. The efforts undertaken by the school in implementing the school literacy movement program are (1) Reading 15 minutes before the lesson, (2) Creating a Literacy Corner and a Text-rich Environment, (3) Multiliteration Learning in Reading and Writing. The obstacles faced by schools in implementing GLS are (1) Low teacher awareness of the importance of literacy activities, (2) Some teachers in high classes are still lacking in discipline, (3) The number of fiction books or picture books in school libraries is still inadequate, (4) Some teachers don't understand examples of the application of literacy movements.
\end{abstract}

Keywords: School Literacy Movement; Elementary Schools; Multiliteration. 
Edutainment : Jurnal Ilmu Pendidikan dan Kependidikan

Volume 7 Nomor 2 Edisi Juli-Desember 2019

\section{PENDAHULUAN}

Situasi pendidikan di Indonesia sekarang menjadi perhatian khusus. Hal ini disebabkan kemampuan membaca anakanak Indonesia masih sangat rendah bila dibandingkan dengan situasi di negaranegara berkembang. Berdasarkan hasil survei UNESCO tentang minat baca terhadap penduduk di negara-negara ASEAN. minat baca di Indonesia berada pada peringkat paling rendah dengan nilai 0,001 persen. Artinya dari 1000 penduduk Indonesia hanya satu yang memiliki minat baca yang tinggi. Minat baca masyarakat Indonesia menduduki urutan 64 dari 65 negara yang diteliti. Hal ini sejalan dengan hasil pengukuran yang dilakukan Programme For International Student Assessment (PISA) tahun 2016 yang dikatakan Yunus Abidin (2017:5), kemampuan siswa dalam literasi membaca, matematika, dan sains menunjukan bahwa siswa SD dan SMP di Indonesia menempati posisi bawah di antara negara yang telah di ukur.

Permasalahan rendahnya minat baca siswa menjadi persoalan serius yang saat ini dialami oleh Negara Indonesia, termasuk di Kepulauan Bangka Belitung. Siswa sebagian besar akan memilih kantin sebagai tempat untuk menghabiskan waktu istirahat atau sekedar duduk-duduk santai di depan kelas daripada di perpustakaan sekolah ataupun membaca buku. Hal ini menunjukan bahwa kegiatan membaca belum menjadi suatu hal yang menarik bagi siswa, bahkan sebagai bagian utama dalam menumbuhkan budaya membaca, tidak semua sekolah mampu menyediakan sarana dan prasarana untuk menciptakan lingkungan nyaman membaca bagi siswa. Kondisi perpustakaan minim buku non pelajaran (novel, buku cerita, ensiklopedia, jurnal, biografi atau buku-buku yang sesuai dengan perkembangan siswa), lingkungan perpustakaan yang tidak tertata rapi serta koleksi buku yang jarang diperbarui dari tahun ke tahun, serta sedikit sekolah yang mengapresiasi kegiatan membaca sebagai prestasi juga menjadi faktor lemahnya kebiasaan membaca.

Menapaki dunia yang kian kompetitif dan pesatnya perkembangan teknologi informasi telah menjadikan kemampuan literasi menjadi hal yang sangat penting bagi setiap individu. Kemampuan seseorang dalam memperlajari dan mengelola informasi menjadi modal penting bagi seseorang dalam meningkatkan pengetahuan, mental, cara berpikir, dan budi pekertinya, sehingga perlunya gerakan literasi yang diterapkan dalam dunia pendidikan. Ilmuwan menganggap literasi sebagai hak asasi warga negara yang wajib difasilitasi oleh setiap negara. Secara sederhana, literasi adalah kemampuan memahami, 


\section{Edutainment : Jurnal Ilmu Pendidikan dan Kependidikan}

Volume 7 Nomor 2 Edisi Juli-Desember 2019

mengelola, dan menggunakan informasi dalam berbagai konteks. Ibadullah (2017:6) mengatakan bahwa literasi bukan hanya sekedar kemampuan dalam membaca dan menulis. Namun, kemampuan itu dimulai dengan kemampuan menyimak, membaca, menulis, dan berbicara. Alberta dalam Ibadullah (2017:8) mengatakan bahwa literasi selain kemampuan dalam membaca dan menulis, tetapi literasi juga dapat menambah pengatahuan, keterampilan, dan kemampuan yang dapat membuat seseorang mampu berpikir kritis, mampu memecahkan masalah dalam berbagai konteks, mampu berkomunikasi secara efektif, dan mampu mengembangkan potensi, serta berpartisipasi aktif dalam kehidupan masyarakat.

Mengatasi persoalan rendahnya minat baca siswa, Pemerintah Republik Indonesia melalui Kementerian Pendidikan dan Kebudayaan Nomor 23 tahun 2015 telah meluncurkan program Gerakan Literasi Sekolah (GLS) yang bertujuan untuk menumbuh kembangkan budaya literasi membaca, dan menulis siswa di sekolah, meningkatkan kapasitas warga dan lingkungan sekolah agar sadar akan pentingnya budaya literasi, menjadikan sekolah sebagai taman belajar yang menyenangkan dan ramah anak, dan menghadirkan beragam buku bacaan dan mewadahi berbagai strategi membaca untuk mendukung keberlanjutan pembelajaran (Suragangga, 2017).

Atmazaki (2017:11) mengatakan GLS merupakan gerakan literasi yang aktivitasnya banyak dilakukan di sekolah dengan melibatkan siswa, pendidik, dan tenaga kependidikan, serta orang tua. Gerakan literasi sekolah dilakukan dengan menampilkan praktik, baik tentang literasi. dan menjadikannya sebagai kebiasaan, serta budaya di lingkungan sekolah. Literasi juga dapat diintegrasikan dalam kegiatan belajar mengajar di sekolah, hingga menjadi bagian tidak terpisahkan dari semua rangkaian kegiatan siswa dan pendidik, baik di dalam maupun di luar kelas. Pendidik dan tenaga kependidikan tentu memiliki kewajiban moral sebagai teladan dalam hal berliterasi. Agar lebih masif, program gerakan literasi sekolah melibatkan partisipasi publik, seperti pegiat literasi, orang tua, tokoh masyarakat, dan profesional.

SD Negeri 1 Koba Kabupaten Bangka Tengah mendukung Program GLS. Hasil observasi peneliti dilakukan di SD Negeri 1 Koba menemukan bahwa sekolah tersebut telah melakukan penerapan gerakan literasi dasar yang mengembangkan kegiatan membaca, menulis, dan berhitung di setiap jenjang kelas. Penerapan gerakan literasi sekolah tersebut membiasakan siswa dalam membaca, sehingga memiliki wawasan 


\section{Edutainment : Jurnal Ilmu Pendidikan dan Kependidikan}

Volume 7 Nomor 2 Edisi Juli-Desember 2019

yang luas. Adapun program khusus penerapan kebiasaan membaca untuk semua warga sekolah, yakni program Literasi sekolah. Program tersebut berupa penerapan kebiasaan membaca 15 menit tiap hari sebelum pembelajaran dimulai. Penerapan GLS di SDN 1 Koba juga berbasis multiliterasi. Multiliterasi didasarkan atas dua argumen yang erat dengan budaya, institusi pendidikan dan tuntutan global. Dalam pandangan ini, multiliterasi merupakan pendekatan belajar yang dikembangkan berdasarkan kesadaran dan pengakuan atas keberagaman dan kompleksitas perspektif budaya siswa dan keberagaman gaya belajar yang dimilikinya. Oleh sebab itu, pendidikan multiliterasi diyakini mampu menjembatani siswa untuk belajar dan berkarya pada abad-21 (Abidin, 2015:57).

Berdasarkan uraian di atas, penulis tertarik melakukan penelitian untuk mengkaji Gerakan Literasi Sekolah Berbasis Pembelajaran Multiliterasi di SD Negeri 1 Koba Kabupaten Bangka Tengah, dalam membangun budaya literasi melalui kreativitas dan inovatif siswanya dalam menyiapkan generasi siap bersaing di era globalisasi.

\section{METODE PENELITIAN}

Metode penelitian yang digunakan dalam penelitian ini yaitu penelitian kualitatif. Penelitian kualitatif yaitu metode penelitian dimana data yang terkumpul dan analisisnya lebih bersifat kualitatif. Penelitian kualitatif disebut juga metode penelitian naturalistic, karena penelitiannya dilakukan pada kondisi yang alamiah (natural setting) (Sugiyono, 2012:41).

Penelitian ini juga bersifat deskriptif, dikatakan demikian karena data yang dikumpulkan berbentuk kata atau gambar. Sehingga laporan hasil penelitian ini berisi kutipan-kutipan dari data sebagai ilustrasi dan memberi dukungan atas apa yang disajikan. Menurut Nazir (1999:63) metode deskriptif yaitu suatu metode dalam meneliti status sekelompok manusia, suatu objek, suatu kondisi, suatu sistem pemikiran ataupun suatu kelas peristiwa pada masa sekarang. Tujuan dari penelitan deskriptif ini untuk membuat deskripsi gambaran atau lukisan secara sistematis, faktual, dan akurat mengenai fakta-fakta, sifat-sifat, serta hubungan antar fenomena yang diselidiki.

Sumber data penelitian terdiri dari data primer dan data sekunder. Sumber data primer, yakni informasi yang diperoleh dari hasil wawancara dengan kepala sekolah, pengawas sekolah, guru, tenaga kependidikan, dan siswa, serta hasil pengamatan di lapangan terkait dengan fisik, dokumen, dan keadaan yang berkaitan dengan implementasi gerakan literasi sekolah. Sedangkan sumber data sekunder penelitian ini digunakan untuk 
melengkapi hasil penelitian, seperti jurnal ilmiah, buku terbitan, dan lain sebagainya. Penelitian dilakukan di SD Negeri 1 Koba Kabupaten Bangka Tengah sebagai tempat pelaksanaan penelitian dan pengolahan data. Objek dari penelitian yaitu program GLS berbasis Pembelajaran Multiliterasi. Subjek dari percobaan ini fasilitas sarana dan prasarana sekolah, seperti perpustakaan, laboratorium, dan kegiatan ekstra kurikuler, lomba-lomba siswa.

Teknik pengumpulan data yang digunakan yaitu wawancara, observasi lapangan dan dokumentasi. Analisis data penelitian ini menggunakan model Miles dan Huberman, yakni reduksi data, penyajian data, dan penarikan kesimpulan (Ahmadi, 2014).

\section{HASIL DAN PEMBAHASAN}

\section{Pelaksanaan Program Gerakan Literasi Sekolah}

Hasil wawancara diperoleh informasi bahwa Dinas Pendidikan Kabupaten Bangka Tengah telah mensosialisasikan program literasi sekolah di SDN 1 Koba sejak tahun 2017 sesuai dengan kebijakan pemerintah melalui Kementerian pendidikan dan Kebudayaan (Kendikbud) mengeluarkan gagasan GLS sesuai Peraturan Menteri Pendidikan dan Kebudayaan Nomor 23 tahun 2015. Sosialisasi diberikan dalam bentuk bimbingan teknis (Bimtek) kepada kepala sekolah dan guru-guru sekolah dasar. Selanjutnya, pengawas dan kepala sekolah melakukan supervisi dan pendampingan pada guru dalam menerapkan program literasi di sekolah. Kepala SD Negeri 1 Koba Bangka Tengah, menjelaskan bahwa sosialisasi pelaksanaan gerakan literasi juga diberikan oleh instruktur dinas pendidikan ketika kegiatan sosialisasi manajemen berbasis sekolah. Selanjutnya, kepala sekolah dan guru-guru di SDN 1 Koba Bangka Tengah menerapkan program GLS dan dikembangkan dengan berbasis multiterasi dengan cara sebagai berikut.

\section{Membaca 15 menit sebelum Pelajaran}

Penerapan membaca 15 menit sebelum pelajaran dapat dilakukan melalui kegiatan membacakan buku dengan nyaring (read aloud). Selain itu, membaca dalam hati (sustained silent reading) merupakan kegiatan membaca 15 menit yang diberikan kepada peserta didik tanpa gangguan. Guru menciptakan suasana tenang, nyaman, agar peserta didik dapat berkonsentrasi pada buku yang dibacanya (Arif, 2017:14). Berdasarkan teori dan hasil pengamatan serta wawancara dengan guru SD Negeri 1 Koba, diperoleh informasi bahwa sekolah telah membuat beberapa pojok literasi dan membuat lingkungan sekolah kaya akan teks. Pojok 
Edutainment : Jurnal Ilmu Pendidikan dan Kependidikan

Volume 7 Nomor 2 Edisi Juli-Desember 2019

literasi tersebut diberi nama pojok baca kelas, gerobak buku, dan reading corner. Pojok baca tersebut berguna untuk mendekatkan buku kepada peserta didik dan sebagai fasilitas kegiatan membaca 15 menit sebelum pelajaran dimulai.

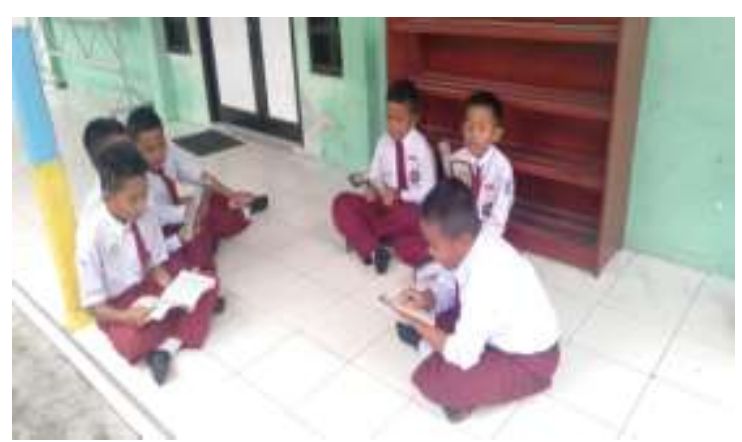

Gambar 1. Membaca 15 Menit Sebelum

Pembelajaran

Adapun bentuk lain yang diterapkan guru dalam kegiatan membaca 15 menit sebelum pelajaran dimulai, yakni membaca di dalam hati secara sendirisendiri, membaca nyaring secara bersamasama, dan membaca dengan dipandu oleh guru. Menurut Billy Antoro, bentuk membaca dongeng sebelum pelajaran dimulai dapat dikembangkan dengan penambahan iringan musik untuk meningkatkan minat peserta didik dalam membaca (Antoro, 2017). Berdasarkan pengamatan yang dilakukan peneliti, siswa SDN 1 Koba dengan disiplin melaksanakan kegiatan tersebut dengan mandiri. Hal ini perlu diapresiasi dan tak lepas dari pembiasaan yang dilakukan oleh guru. Kepala sekolah mengakui bahwa pelaksanaan kegiatan membaca 15 menit sebelum pelajaran dimulai belum dilaksanakan secara disiplin oleh semua guru kelas. Guru kelas tinggi juga mengakui bahwa mereka terkadang tidak memandu peserta didik untuk melaksanakan kegiatan membaca 15 menit sebelum pelajaran dimulai.

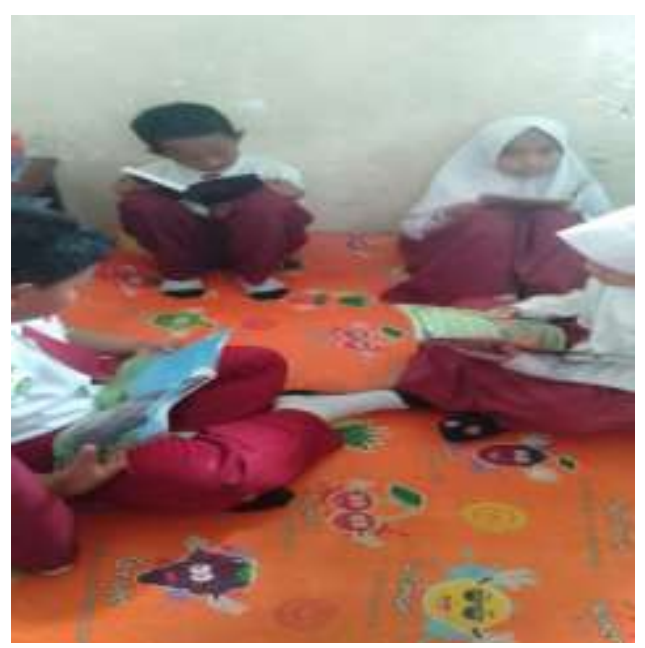

Gambar 2. Membaca 15 Menit Sebelum

$$
\text { Pembelajaran }
$$

\section{Membuat Pojok Literasi dan Lingkungan yang Kaya Teks}

Arif mengatakan (2017:14) penerapan GLS juga diterapkan dengan pembangunan lingkunan fisik sekolah yang kaya literasi antara lain: (a) penyediaan perpustakaan sekolah, sudut baca, dan area baca yang nyaman; (b) pengembangan sarana lain (UKS, kantin, kebun sekolah); dan (c) penyediaan koleksi teks cetak, visual, digital, maupun multimodal yang mudah diakses oleh seluruh warga sekolah, dan (d) pembuatan bahan kaya teks (print-rich materials). 
Edutainment : Jurnal Ilmu Pendidikan dan Kependidikan

Volume 7 Nomor 2 Edisi Juli-Desember 2019

Pembangunan lingkungan fisik yang diterapkan dalam membangun GLS di SDN 1 Koba salah satunya pojok baca atau sudut baca yang digunakan sebagai wadah untuk peningkatan minat baca siswa. Penerapan GLS dengan membiasakan budaya membaca didukung oleh sudut baca yang dimanfaatkan siswa ketika waktu istrihat dan waktu senggang lainnya. Pojok baca dianggap efektif untuk membiasakan dan menumbuhkan minat baca siswa.
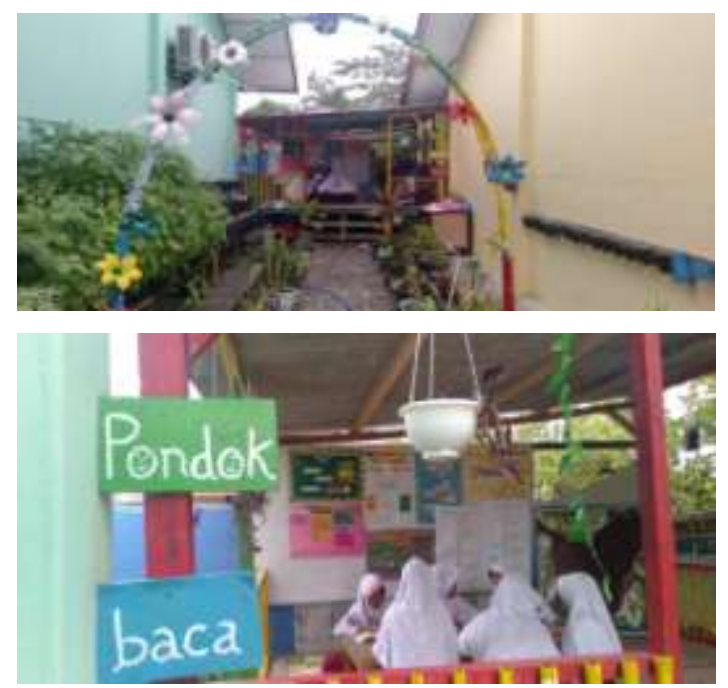

Gambar 3. Pojok Baca yang Sedang

Dimanfaatkan Siswa untuk Membaca

Pondok baca yang dibangun di SDN 1 Koba sebagai wadah penerapan GLS menjadi sebuah upaya untuk menumbuhkan minat baca siswa, dan hal ini dipandang efektif. Setiap istirahat dan waktu senggang siswa memanfaatkannya dengan membaca, sehingga siswa terbiasa, dan program ini juga menjadi faktor tingginya tingkat prestasi siswa di SDN 1 Koba. Berdasarkan hasil pengamatan dan wawancara dengan warga sekolah diperoleh informasi bahwa sekolah juga menerapkan lingkungan sekolah kaya akan teks. Adapun upaya yang dilakukan guru untuk menciptakan lingkungan yang kaya teks, yakni 1) menampilkan karya peserta didik di dinding kelas, 2) menghiasi meja siswa dan dinding sekolah dengan baner yang berisi kata-kata motivasi hidup sehat, disiplin, rajin beribadah, membuang sampah pada tempatnya, dan dokumentasi kegiatan warga sekolah.
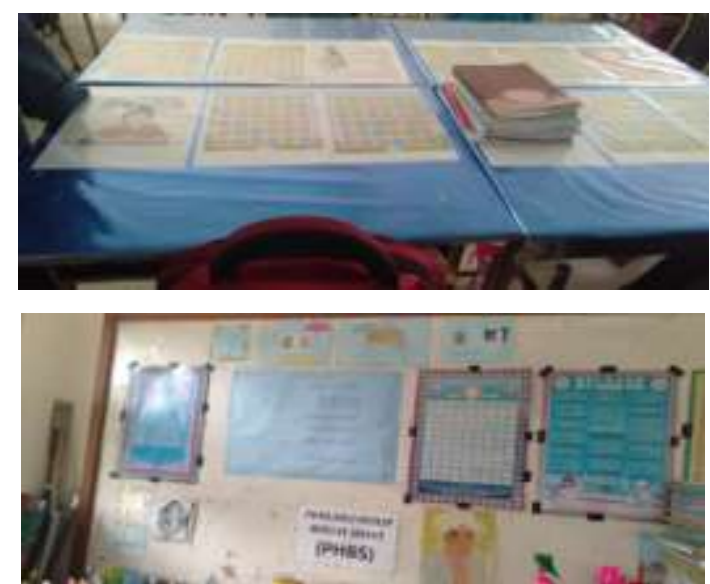

Gambar 4. Meja dan Lingkungan Kelas

Siswa Kaya dengan Teks

Guru menerapkan lingkungan kaya dengan teks dengan tujuan membiasakan siswa untuk membaca teks, salah satunya dengan menempel poster-poster di meja masing-masing siswa. Upaya ini dianggap berhasil dikarenakan siswa akan terbiasa melihat teks dan akan terbiasa membaca teks, sehingga mampu meningkatkan kebiasaan membaca siswa di SDN 1 Koba. 
Edutainment : Jurnal Ilmu Pendidikan dan Kependidikan

Volume 7 Nomor 2 Edisi Juli-Desember 2019

Pembelajaran Multiliterasi Membaca dan Menulis

Cope dan Kalantziz (2005) menyatakan penggunaan istilah multiliterasi didasarkan atas dua argumen yang erat dengan budaya, institusi pendidikan dan tuntutan global. Dalam pandangan ini, multiliterasi merupakan pendekatan belajar yang dikembangkan berdasarkan kesadaran dan pengakuan atas keberagaman dan kompleksitas perspektif budaya siswa dan keberagaman gaya belajar yang dimilikinya. Oleh sebab itu, pendidikan multiliterasi diyakini mampu menjembatani siswa untuk belajar dan berkarya pada abad-21 (Abidin, 2015:57).

Pada proses pembelajaran multiliterasi membaca, siswa diajak untuk membaca multikonteks, multimedia dan multibudaya. Multikonteks berarti teks yang dibaca beraneka ragam dan merujuk kepada berbagai bidang ilmu meliputi buku bacaan, cerita motivasi, dan informasi yang berasal dari internet. Multimedia berarti sumber bacaan tidak hanya dari buku konvensional dan Koran, tetapi juga bisa membaca e-book atau koran edisi web. Multibudaya berarti teks yang dibaca harus mewakili berbagai budaya Indonesia dan berkarakter asli masyarakat Indonesia.
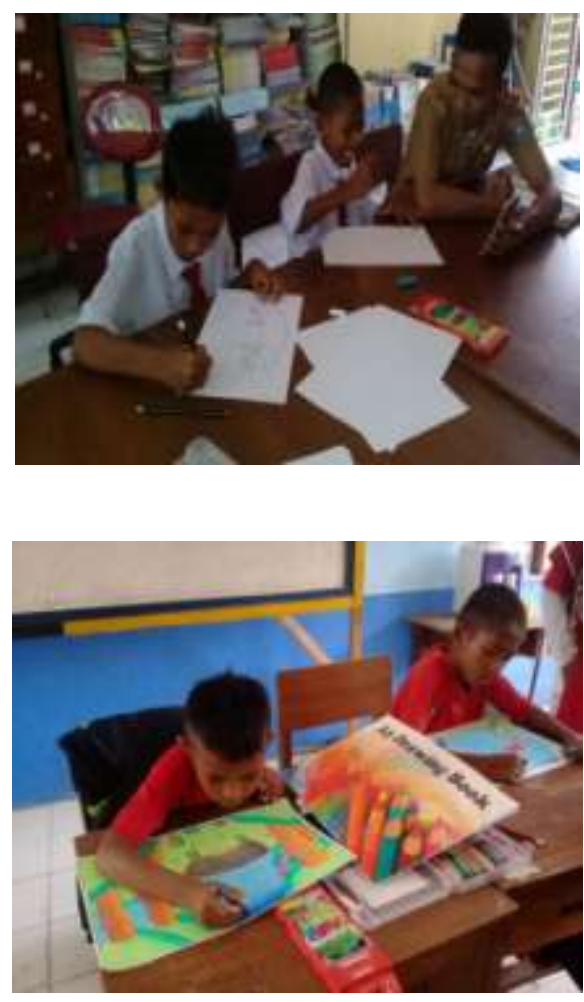

Gambar 5. GLS Berbasis Multiterasi Seni Budaya

GLS di SDN 1 Koba diterapkan dengan basis multiterasi melalui pendekatan budaya. Pengembangan konsep multiliterasi dalam dunia pendidikan sebenarnya tidak terlepas dari konsep berbasis seni, multiple ways of knowing, dan multiintelegensi yang telah terbukti mengembangkan kreativitas siswa, pengembangan keterampilan dalam bidang teknologi dan komunikasi dan memahami perbedaan sosial budaya. Oleh karena itu pembiasaan keterampilan siswa melalui seni juga menjadi fokus utama GLS di SDN 1 Koba, salah satunya dengan mengenalkan budaya lokal serta flora fauna lokal melalui seni kepada siswa. 
Edutainment : Jurnal Ilmu Pendidikan dan Kependidikan

Volume 7 Nomor 2 Edisi Juli-Desember 2019

\section{Kendala yang dihadapi SDN 1 Koba dalam Melaksanakan Program GLS}

Adapun beberapa kendala yang dihadapi sekolah SDN 1 Koba dalam pelaksanaan gerakan literasi sekolah masih rendahnya kesadaran guru terhadap pentingnya kegiatan literasi, sehingga jika tidak dipantau guru tidak terlibat aktif dalam pelaksanaannya dan berpengaruh pada pelaksanaan tanggung jawab mereka dalam melaksanakan program-program gerakan literasi sekolah. Kepala sekolah mengungkapkan bahwa sebagian guru pada kelas tinggi masih kurang disiplin dalam melaksanakan kegiatan membaca 15 menit sebelum pelajaran dimulai. Kemudian buku pengayaan anak yang sesuai sulit ditemukan. Pengelola perpustakaan mengungkapkan bahwa jumlah buku fiksi atau buku cerita bergambar di perpustakaan sekolah masih kurang memadai.

Sebagian guru juga tidak memahami contoh-contoh penerapan gerakan literasi. Meskipun semua guru telah mengikuti bimbingan teknik program GLS. Namun, hasil wawancara penulis dengan guru masih menunjukkan bahwa sebagian guru masih belum mengetahui berbagai contoh pelaksanaan program gerakan literasi sekolah.

\section{KESIMPULAN DAN SARAN}

Berdasarkan uraian hasil pembahasan di atas, maka dapat dikatakan bahwa Pelaksanaan program GLS di SDN 1 Koba Bangka Tengah berada pada tahap pembiasaan. Upaya-upaya yang dilakukan sekolah dalam pelaksanaan program GLS, yakni dengan membiasakan siswa membaca 15 menit sebelum dimulai pembelajaran, mendekatkan buku ke siswa sekolah dengan cara membuat beberapa area baca ataupun pojok baca dan membuat lingkungan yang kaya akan teks, serta melaksanakan kegiatan literasi sekolah berbasis multiliterasi budaya lokal dan seni.

Kendala yang dihadapi SDN 1 Koba Bangka Tengah dalam pelaksanaan GLS, yakni masih rendahnya kesadaran guru terhadap pentingnya kegiatan literasi, sebagian guru pada kelas tinggi masih kurang disiplin dalam melaksanakan kegiatan membaca 15 menit sebelum pelajaran dimulai, bahwa jumlah buku fiksi atau buku cerita bergambar di perpustakaan sekolah masih kurang memadai dan sebagian guru juga tidak memahami contoh-contoh penerapan gerakan literasi. 
Edutainment : Jurnal Ilmu Pendidikan dan Kependidikan

Volume 7 Nomor 2 Edisi Juli-Desember 2019

DAFTAR PUSTAKA

Abidin, Yunus, dkk. 2015. Pembelajaran Literasi Strategi Meningkatkan Kemampuan Literasi Matematika, Sains, Membaca, Dan Menulis. Jakarta: Bumi Aksara.

Agustina, T. Y., Ansori, Y. Z., \& Saputra,

D. S. (2019, Oktober). Pengaruh Model Pembelajaran Multiliterasi Terhadap Keterampilan Menulis Narasi di Kelas V Sekolah Dasar. In Seminar Nasional Pendidikan (pp. 896-902).

Ahmadi, R. 2014. Metodologi Penelitian Kualitatif. Yogyakarta: Ar-Ruzz Media.

Antoro, B. 2017. Gerakan Literasi Sekolah dari Pucuk Hingga Akar (Sebua Refleksi). Banjarmasin: Direktorat Jenderal Pendidikan Dasar dan Menengah Kementerian Pendidikan dan Kebudayaan.

Atmazaki, dkk. 2017. Panduan Gerakan Literasi Nasional, Jakarta: Tim GLN Kemendikbud.

Cope dan Kalantzis. (2005). Multiliteracies

Literacy Learning and The Design of Social Futures. New York. Rotledge, Taylor \& Francis Group.

Malawi, Ibadullah, dkk. 2017.

Pembelajaran Literasi Berbasis Sastra Lokal. Jawa Timur: CV. AE Media Grafika.
Sugiyono. 2019. Metode Penelitian Pendidikan Pendekatan Kuantitatif, Kualitatif, dan $R \& D$. Bandung: Alfabeta. 